\title{
LA POESÍA DE RITA MARÍA MAGDALENO: EN BUSCA DEL CORAZÓN MATERNO
}

\author{
Bruce-Novoa* \\ The transformations of instinct, on which our cultural \\ adaptability is based, may also be permanently or \\ temporarily undone by the experiences of life. \\ Undoubtedly the influences of war are among the \\ forces that can bring about such regression. \\ "Thoughts on War and Death," \\ Sigmund Freud.
}

RESUMEN: "La poesía de Rita María Magdaleno: en busca del corazón materno". En su poemario Marlene Dietrich, Rita Hayworth, \& My Mother (2003), Magdaleno, poeta chicana de Arizona, busca a su madre, un avatar de la Malinche. Los lectores reconocerán temas de la literatura chicana: la frontera como escenografía, el amor entre el conquistador y la mujer nativa, la mujer embarazada, abandonada por el soldado extranjero. Sin embargo, esta temática sufre un enajenamiento revelador al trasladarse a Alemania. Después de la Segunda Guerra Mundial, el conquistador, un soldado chicano de Arizona, se enamora de una adolescente alemana. Cuando no la lleva consigo a EEUU, ella, aunque indocumentada, lo sigue con la hija. El efecto se parece al Unheimlich de Freud, puesto al día por Homi Bhabha. La reunión con su familia materna en 1989 guía a Magdaleno a la historia del nazismo, una ideología que puede leerse como un reflejo del nacionalismo cultural chicano. Al frustrarse la reunión con su madre, Magdaleno logra un tipo de reencuentro en un subtexto de metáforas de la naturaleza.

PALABRAS CLAVE: Literatura chicana, Alemania, Malinche, Unheimlich.

ABSTRACT: "The Poetry of Rita María Magdaleno: In Search of the Maternal Heart". In her poetry book, Marlene Dietrich, Rita Hayworth, \& My Mother (2003), Magdaleno, Chicana poet from Arizona, searches for her mother, a version of the Malinche. Readers will recognize themes from Chicano literature: the border setting, love between conqueror and native woman, the

* Universidad de California, Irvine (jbruceno@uci.edu). 
pregnant woman abandoned by the foreign soldier. However, these themes undergo a revealing estrangement when reset in Germany. In post-World War II, the conqueror, a Chicano soldier from Arizona, fell in love with a German adolescent. When he did not take her along back to the U.S.A., although lacking documents, she followed him with her daughter. The effect resembles Freud's Uncanny, up-dated by Homi Bhabha. The reunion with her maternal relatives in 1989 guides Magdaleno to the history of Nazism, an ideology that can be read as a reflection of Chicano cultural nationalism. When the reunion with her mother is frustrated, Magdaleno achieves a reencounter of sorts through a subtext of nature metaphors.

KEY WORDS: Chicana, Germany, Malinche, Uncanny.

A estas alturas la literatura chicana es una realidad muy conocida, definida por la crítica académica y aceptada por la oferta y demanda del mercado. Su discurso ha quedado codificado tanto por sus características más comunes, como por las voces periféricas que le confieren variedad. La mayor parte de lo que se ha producido no sale del círculo de lo ya establecido; o sea, casi todo lo nuevo aparece dentro de los lugares comunes que, a fuerza de la repetición, se ha convertido en cliché. Ya no nos sorprende encontrar en una obra chicana, por ejemplo, referencias a la frontera o border, como ahora se usa en ambos lados de la línea divisoria; o a la madre, como símbolo del pasado perdido, y aun a la Malinche, como sinónimo de mujer autóctona maltratada por su familia, la cual se venga creando la nueva familia mestiza al entregarse al soldado conquistador. La desaparecida madre-Malinche a la que tenemos que rescatar de la ignominia para reconciliarnos con nuestras raíces culturales, con los Aztecas o Mayas, con la inmigración ilegal — los mojados - etc. etc. También estamos demasiado acostumbrados a los textos que mezclan idiomas que brindan al texto el aspecto de espacio del continuo proceso de hibridización, escritos que se presentan como el testimonio de la búsqueda de las raíces en una cultura extranjera, búsqueda que resulta ser la intención de obtener una identidad mestiza lograda por el o la autora dentro de una etnicidad que, a pesar del viaje a la "madre patria", resulta ser fundamentalmente estadounidense en su orientación y su discurso cultural de minoría en Estados Unidos. Todo esto lo encontramos en la 
colección de poesía Marlene Dietrich, Rita Hayworth, \& My Mother ${ }^{1}$ de Rita María Magdaleno.

El libro se estructura a partir del viaje de la autora en busca de su madre. Después de un poema introductorio que nos presenta un imagen de la madre en su juventud, poema que por cierto aparece en una página sin número como si no perteneciera a la colección en sí, la primera sección nos relata este viaje en plena zona fronteriza. Como resultado de la guerra se trazó esta frontera para dividir en dos países lo que en realidad era el territorio de una sola nación, otro cliché de la literatura chicana. Magdaleno se va acercando a la frontera dentro de una atmósfera de anhelo, de esperanza, de la posibilidad de un encuentro con su origen perdido.

[...]Here, I can feel an old separationof heart and land, of mother and daughter. This trip is like going back more than forty years and I' $m$ thinking of my dead mother, of the borders we once constructed between one another (p. 4).

No podría ser más claro el afán de equiparar la relación entre la familia y la nación dividida. En este contexto la frontera toma el aspecto de una construcción arbitraria que separa lo que por naturaleza debiera estar unido: madre e hija o el territorio nacional. El viaje relatado en el texto "this journey back/ to my Mother" (p. 17) se dirige a la resolución de esta condición de enajenamiento. La separación se expresa, significativamente, como una división entre el corazón y la tierra/país, imagen en la cual se funde lo humano y el mundo/territorio. Va en busca de la unión del cuerpo total de su existencia, el corazón restituido en su cuerpo familiar/social. Pero la construcción del verso equipara heart $=$ mother y land = daughter, lo cual implica que tendrá que lograr reunirse con la madre para restituir la deseada integridad de ese cuerpo/tierra/patria. Al final del poema anuncia la esencia del proyecto dentro del símil de la madre/frontera:

1 Rita María Magdaleno, Marlene Dietrich, Rita Hayworth \& My Mother, Tucson, University of Arizona Press, 2003. Las páginas entre paréntesis corresponden a esta edición. 
[...] wet border. She is

wide open like a mother

who is ready

to give birth (p. 4).

La autora se desplaza hacia un momento que será el renacimiento del país de origen reunificado y simultáneamente el de ella misma como producto de su reencuentro con la madre/patria. Y definitivamente ese producto será híbrido en su materia prima, reflejado, sobre todo, en el lenguaje interlingüe, en sí una fusión de lo público, el inglés y lo privado, los idiomas de sus padres.

Si dejamos de lado por ahora el título, podemos anticipar el itinerario del viaje desde la supuesta etnicidad chicana de la autora. El texto no nos desilusiona. La protagonista visita a la familia materna, explora la zona de su propio nacimiento evocando los detalles pintorescos que la caracterizaron, llega a conocer a sus parientes, descubre la represión que las mujeres sufrieron dentro de un patriarcado tradicional, y aun llega a desenmascarar al abuelo como el violador de la madre. También confronta el tema del prejuicio racista, que en este caso es de índole intrafamiliar, en contra de la autora mestiza que regresa de Estados Unidos en busca de sus raíces maternas. Todo esto nos ayuda a comprender lo que motiva a la madre a abandonar su mundo conocido - familia, amigos, región, país - para seguir al conquistador. Dentro del marco que el texto abre en tiempo y espacio, se crea el escenario para el relato del encuentro, el enamoramiento y la relación íntima entre sus padres, representados en los términos de la simbología chicana establecida: él, un soldado conquistador; ella, la nativa de la zona conquistada. Más tarde, la madre asume la imagen de la mujer abandonada que sigue a su hombre cuando éste tiene que emigrar a Estados Unidos sin ella, dejándola embarazada. La madre resuelta y valiente no permite que ni la distancia ni el destino la marginen a ella ni a su hija, y viaja a la Unión Americana impulsada por el típico sueño de los inmigrantes — "your/ immigrant dream” (p. 49). El primer poema de la última sección del libro recoge 
el eco del primero de la colección para fundirlo con el nacimiento de la autora misma. "[...]It was/ A shining moment \& you believed America was the pure/ dream - my face, a dark moon surfacing between your/ thighs" (p. 79).

Más tarde la autora se autocaracteriza con más clichés: "dark daughter, mojada" y "a wetback escaping to an American education" (p. 88). Pero en este caso escapaba hacia el mundo méxico-estadounidense, personificado en la figura del padre y ubicado geográficamente en el estado de Arizona. Y cuando el matrimonio fracasa, la hija se siente dividida por la distancia entre sus padres, una frontera que continúa aún después de morir la madre. Cuando la hija invita al padre a acompañarla a visitar la tumba de la madre, éste rechaza su esfuerzo por reunirse por última vez. "Meet me at the headstone, bring some roses/ I tell him. I'm afraid to fly, honey,/ Don't think I'll ever go back, he says" (p. 73). Ya nada ni nadie puede restaurar el idilio roto, pero el texto logra lo que tanta literatura chicana se ha propuesto desde el principio: rescatar del olvido y la incomprensión las imágenes de las figuras que determinan el bienestar de la generación actual, que siente la amenaza de la pérdida de su axis mundi familiar y/o cultural. Al recobrar las imágenes, la hija las ubica de nuevo en su contexto para comprender las fuerzas que las crearon y, a la vez, descifrar su propio papel y significado en la tradición. ${ }^{2}$

De ese modo la autora rescata la tradición amenazada para organizar lógicamente su presente y sobre esa base proyectarse hacia el futuro, un futuro mestizo, híbrido que se anticipa ya en un bilingüismo incipiente. El inglés predomina en el texto, aunque Magdaleno también utiliza algunas frases en español, que traduce al inglés para los lectores, por ejemplo, "alas y restos,/bir-dwings/ \& ashes" (p. 15) o "una hija natural,/ illegitimate child" (p. 52). Pero ese futuro mestizo adquiere una identidad étnica específica cuando la autora, en un momento de crisis frente al racismo descubierto en la figura de un tío, caracteriza

2 Cfr. Juan Bruce-Novoa, Chicano poetry, A response to Chaos, Austin, University of Texas Press, 1982. 
su esencia: "my Azteca heart" (p. 28). Dentro del discurso de la colección, el atribuir al centro vital —el corazón que anda buscando desde el principio - un identidad azteca evoca uno de los códigos chicanos más trillados: el aztlanismo. Frente a los descubrimientos hechos al indagar los orígenes maternales, la autora afirma su identidad étnica, una identidad que no hubiera tenido sentido para ninguno de su padres, pero que en una situación de amenaza es una respuesta ad hoc.

Hasta aquí nuestra lectura ubica el texto de Magdaleno firmemente en el contexto central de la literatura chicana. Sin embargo, sería una lectura peligrosamente parcial basada en el afán de privilegiar el discurso chicano sobre otros. Efectivamente, los elementos que acabamos de agrupar, mientras nos proveen bastantes signos para justificar la inclusión del texto dentro de la literatura chicana, no lo dominan. O sea, otro discurso ocupa más espacio, otra geografía sirve de escenario y aun otro idioma compite con el español dentro del juego de diferencia con el inglés. Todo esto lo anuncia el título, Marlene Dietrich, Rita Hayworth, \& My Mother.

En el título formado por los nombres de dos actrices famosas y la madre, a primera vista nada nos permite relacionar a las estrellas con la madre. Es una enumeración, sin verbo o complementos que pudieran orientarnos. Sólo podemos suponer que de alguna forma las estrellas son el contexto que la autora desea establecer para la madre como un principio de nuestro viaje, la lectura. Comenzamos, entonces, con una mujer alemana y otra estadounidense de ascendencia británico-española. ${ }^{3}$ Lo más significativo es que las actrices comparten un contexto en el cine internacional de mediados del siglo XX y otro de la categoría "Love

3 A pesar de los esfuerzos recientes por parte de la crítica chicana para convertir a Rita Hayworth en mexicana, su ascendencia quedó registrada en su acta de nacimiento: "born Margarita Carmen Dolores Cansino on October 17, 1918 at New York Nursery and Child's Hospital, in New York City. Her parents were Volga Hayworth, of Irish and English descent, and Eduardo Cansino, who came from Seville, Spain". En Claudia de la Hoz, http://members.tripod.com/ claudia79/early.html. 
Goddess", símbolo del objeto de deseo sexual masculino. La madre, a quien le falta nombre en el título de la obra, emerge de este contexto. Los lectores asumen su primera impresión sobre la madre como un juego entre Alemania y Estados Unidos en una época histórica específica, juego que gira alrededor del tema del imaginario del deseo. En el centro de esta primera presentación está lo ilusorio de la imagen del celuloide frente a la realidad concreta de "my mother"—o sea, la realidad de ésta se satura de las sugerencias brindadas por las dos estrellas, pero se nos pone de manifiesto que el llegar a la realidad de la mujer será difícil y quizá requerirá de una desmitificación. La lectura del texto confirma esa primera impresión y aclara el proyecto de la autora.

Por un lado, Magdaleno logra recontextualizar los clichés de la literatura chicana dentro de su situación personal de chicana alemana. Magdaleno nació en 1947 en Augsburg, Alemania, hija de una nativa de la región y un joven soldado estadounidense méxico-americano de Arizona. O sea, la temática chicana se revitaliza al aparecer fuera de contexto, forzando a los lectores a verla dentro de una red de asociaciones distintas, raras, capaces de sacarles nuevas resonancias y renovar las trilladas. En términos de Freud, los poemas de Magdaleno producen el efecto llamado unheimlich, esa combinación de lo familiar y lo extraño, lo bien conocido y lo desconocido. Su centro, Heim (casa u hogar) es el espacio familiar, la residencia íntima donde uno reside a gusto en lo conocido. Pero cuando algo surge de ese contexto que nos parece igualmente extraño y aun amenazante, nos perturba la contradicción. Lo unheimlich es el efecto que causará el libro de Magdaleno para los lectores acostumbrados a la literatura chicana. En esto estriba su fuerza renovadora. La temática y los recursos, que con base en la repetición han perdido su fuerza evocadora, cobran una nueva vitalidad en Marlene Dietrich, Rita Hayworth, \& My Mother.

Podemos apreciar este efecto en el poema con el que se abre la primera sección del libro: "Grenze". La autora se encuentra en Alemania en 1991 a bordo de un tren, camino a la zona donde hacía poco tiempo todavía existía una frontera que, después de la Segunda Guerra Mundial, 
dividió la nación en dos países, la República de Alemania del oeste y la Alemania Democrática del este, esta última controlada por el comunismo como satélite de la Unión Soviética. Entre ambos lados surgió una frontera militarizada, cerrada a fuerza de bardas, alambre de púas, torres de vigilancia y pena de muerte para los que se arriesgaban a violarla. La autora la evoca en forma bilingüe: "they were split/ by the border, die Grenze, for more/ than forty years" (p. 3). Esta es "the border" a que se refiere la autora en los versos citados arriba en los cuales compara la apertura de la frontera a una mujer que da a luz. Así comienza el proceso de desplazamiento de los clichés chicanos. El tema de la frontera se desdobla para desterritorializarse del afán de acapararlo por parte del discurso chicano, universalizándose al mostrar que no es exclusiva a la situación méxico-estadounidense. También muestra que a pesar de todo lo dicho acerca de esta frontera, la situación es realtivamente inocua en comparación con la frontera militarizada entre las dos Alemanias - a pesar de las víctimas que cobra la frontera méxico-estadounidense, nunca se ha cerrado total y sistemáticamente. Además, la fluidez de las divisiones políticas — se imponen y desvanecen - mina la solidez de toda frontera. Así Magdaleno logra crear una escenografía imaginaria en la cual las fronteras se reflejan mutuamente, y dentro de esta novedad que ofrece surge la metáfora del nacimiento, que más tarde resulta ser el de la nueva mestiza, la chicana alemana Rita María Magdaleno.

Lo mismo pasa con la imagen de la pareja arquetípica: la madre nativa/Malinche y el padre extranjero/conquistador. Primero, vemos que la situación es de nuevo universal: podría pasar en cualquier lugar y época. Segundo, la actitud de conquistador no es europea, sino global. En este caso el conquistador es chicano, el mismo que luego le sirve a la autora como vínculo a su "azteca heart". O sea, el acto de conquista, tan denunciado en la literatura chicana, es lo que aquí permite la afirmación étnica, lo cual revela que la conquista fue - es - esencial al mestizaje. Dentro de este contexto, la madre alemana encarna la experiencia de la Malinche y se nos da a entender que ésta no es una característica específica a una cultura o a un momento histórico, sino más bien es ubicua. Lo 
que indica que se le puede atribuir a la política nacionalista, que a su vez solemos asociar con el patriarcado. La autora muestra cómo su madre, su abuela y sus tías vivieron en un régimen de represión masculina que permitía el abuso y la explotación de las mujeres, y que aun esta actitud se elevó a programa nacional con el fascismo.

De este abuso que sufrió la madre de la autora a manos tanto de su propio padre como del régimen político — con la aquiescencia de su propia madre (p. 12) - se ve liberada por los conquistadores estadounidenses. Después de revelar ese abuso, el lector comprende por qué la joven alemana colaboró con los conquistadores hasta entregarse sexualmente a uno de ellos, quien la embaraza y abandona. La autora se representa como la hija de esta unión prototípica. En su texto Magdaleno ofrece otra de las ya muchas justificaciones de la Malinche creadas por la literatura chicana.

El hecho de que la situación de la Malinche se evoque en la memoria de los lectores como modelo para la situación de la autora y sus padres, vincula el pasado con el presente dentro de una repetición arquetípica de tipos universales. En otro poema, "High Summer" (pp. 21-23) lo extiende más hacia el futuro al mostrarnos la imagen de otra madre e hija, checoslovacas, en plena frontera. La autora relata su viaje a Praga donde representa el papel de turista en el Tercer Mundo, que era la situación en que se encontraban los satélites de la vieja Unión Soviética a principios de los años noventa. Al viajar de regreso hacia Alemania se acerca a la frontera con sus compras típicas como cualquier turista: "To the border, our shopping bags full/ of cherries, Oblaten, ouzo and duty-free/ cartons of Marlboros" (p. 22). Palabras como border y duty-free ubican la acción dentro de la zona fronteriza y allí aparece otro avatar de la pareja madre/hija víctimas de otra invasión conquistadora.

I am thinking about

that mother, how she stood empty-handed

beside her daughter, how they watched

our silver bus pull away, quickly.

Now the sun drips orange behind wild

hills curving all around us 
and I wonder what is left

for that woman to give her daughter

besides a small space at that roadside

stand, to sell cherries. And sometimes

to get cheated by people like us,

tourists who need to take something

home, who expect to travel with full

pockets across the border. High

summer, the moon swelling up

fat and yellow over the border.

Over each row of naked

cherry trees (pp. 22-23).

Las dos checas son víctimas de una nueva forma de conquista, la globalización. El lugar del conquistador lo ocupa ahora el turista que entra, se divierte, adquiere los objetos de consumo que desea —nótese que con la excepción de las cerezas el resto son objetos de producción extranjera - y regresa con su botín de ofertas. Quizá con algo más significativo, pues el viaje le permite afirmar el derecho de cruzar la frontera sin sacrificar nada: los bolsillos siguen llenos. Nótese cómo Magdaleno crea el efecto de cruzar y recruzar la frontera al repetir la palabra dos veces en tres versos, impresión que acentúa al terminar la oración sobre el viaje de los turistas con la palabra "border", y luego dirigir la mirada de los lectores, una vez más, hacia el otro lado, o sea, forzarla a cruzar la frontera de nuevo en la oración siguiente. La imagen de la luna, vista sobre la República Checa desde Alemania, esto es sobre el este desde el oeste, también juega con los primeros versos del poema en que se ve la luna a la inversa, hace del poema completo un cruce de caminos sobre la frontera entre los dos países. Nótese también cómo Magdaleno, al utilizar la naturaleza como un elemento en el juego, añade una perspectiva más expansiva que nos permite ver la problemática humana desde una distancia trascendental para apreciar el significado del encuentro entre particulares.

El poema culmina con la imagen de los cerezos desnudos de la fruta, que la señora vendió para poder ofrecerle algo a su hija. Resuena el eco de la pregunta ya planteada por la autora: ¿al acabarse la mercancía, qué 
le queda a la madre que pueda ofrecerle a la hija más que el lugar mismo de transacción? Agotadas las cerezas, le queda sólo su propio cuerpo o el de su hija - y el uso coloquial de cherry como virginidad en el inglés estadounidense surge como respuesta a la pregunta. Magdaleno centra la problemática de la conquista que deviene en globalizacion y en la explotación del cuerpo femenino.

La estructura de "High Summer" muestra en miniatura lo que Magdaleno hace con la relación de sus padres. Comienza con la aparente inocencia de la diversión social, que poco a poco se transforma en una confrontación entre el deseo de escapar de la pobreza y el deseo por parte de los otros de aprovecharse de los pobres. Al final muestra los resultados de esa confrontación, no en forma de una respuesta definitiva, sino como un continuo movimiento entre perspectivas desde distintos puntos de vista, que quisieran ser ese deslinde definitivo entre opuestos binarios, pero que quedan relegados a la relatividad oscilante. Lo hace en todos los niveles de significación, pero por razones de espacio tendremos que enfocarnos en algunos de los más importantes respecto a la preocupación central —el asunto del corazón - la experiencia de su madre que la llevó a concebir: la relación de sus padres, la familia materna y el significado de esa historia recuperada.

La recreación de la relación entre los padres comienza en ese poema inicial que aparece como prefacio sin número de página, "My Mother's Hair". La autora evoca a su madre en una escena de inocencia juvenil, repleto de signos optimistas de primavera prometedora:

When I think of my mother at seventeen, I see her sitting on the floor of the warm kitchen on Brunnenlechgässchen. It is 1946 and the war is over, a bright spring afternoon.... My mother has gotten a perm, curls shining like copper. "Pretty girl," my father is singing and dancing around her." "Yes, you are my pretty girl," smell of bread rising, calendulas on the table. 
Martha, my mother's best friend, is riding away on her motorcycle.

The war is over.

My mother's hair is shining (p. ix).

Todo es ligero, alegre, fresco, juguetón, ingenuo. La madre y el padre parecen niños en pleno juego inocente, ella sentada en el suelo mientras él baila y canta alegremente a su rededor. El pan es pura promesa, tan fresco que todavía ni está listo para el horno, y en la mesa se encuentran caléndulas en flor para dar un toque de amarillo brillante a la cocina, en juego con el brillo de cobre del pelo de la madre. Tanto las flores como la madre apenas han brotado. Toques ligeros aparecen en el nombre de la calle que figura en el diminutivo alemán —Brunnenlechgässchen - y en la imagen de la libertad de movimiento — la amiga en la motocicleta. Sin embargo, no debemos pasar por alto que el poema comienza no en el pasado como una observación de la realidad de esa relación, sino como la imagen que la autora evoca cuando recuerda a su madre. O sea, nuestra primera imagen de la pareja es la que más le satisface a la autora, pero por alguna razón se le da el aspecto de paratexto como si no tuviera lugar en el texto mismo. Por lo mismo no coincide con la realidad tal cual se revelará en los poemas que siguen.

Los 19 poemas de la primera sección tampoco tratan la imagen de la madre; sólo aparece en la segunda. Antes, la autora nos presenta a sus parientes alemanes y se enfrenta al hecho histórico que marcó la época en que se formó su madre, el nazismo. O sea, al volver a la imagen de los padres cuando fueron novios, después de la guerra, ya no domina lo juvenil, lo brillante, lo primaveral, ni la ingenua promesa del amor inocente. El contexto familiar-social sufre un reajuste a través de las imágenes de los crímenes del régimen nazi, sobre todo los que acontecieron en Dachau, el campo de exterminación que quedaba cerca de Augsburgo donde vivía la madre y sigue viviendo la familia materna. De este contexto surge la figura siniestra de un tío que pertenecía al ínfimo grupo SS (Schutzstaffel o camisas negras) que, según la autora, la hubiera matado 
"without hesitation" por ser ella mestiza de "mixed blood"(p. 28). La ilusión de alegría juvenil e inocencia del poema inicial desaparece frente a la acumulación de imágenes teñidas de muerte, represión, sufrimiento y vilezas. Las flores en la cocina se transforman en las rosas blancas, signo de la organización estudiantil antinazi, cuyos miembros jóvenes fueron condenados a la muerte. La imagen del pelo brilloso de la madre se transforma en el brillo verde del pelo rubio de un niño en el momento que un bombardeo incendiaba el aire mismo, "the dazzling moment/ he was torched,/ bone fused/ to metal,/ a skeleton/ pedaling/ the charred/ bike" (p. 13). La primera menstruación de la madre se contextualiza dentro de la negatividad nazi: en un campo de trabajo forzado la madre pela papas y piensa en la muerte de su hermano en la guerra; la autora luego pregunta, "What do we call this memory/ of death, this grief of children?” (p. 11). Y se revela que cuando tenía diez años la madre fue abusada sexualmente por su propio padre (p. 31), imagen que sólo en la página 50 se explicará con detalles que asocian este acto a la experiencia de la madre que casi muere en un ataque aéreo.

Después de todo esto, cuando la autora vuelve a la imagen de su madre después de la guerra, en el primer poema de la segunda sección, ya no es un recuerdo imaginario inventado por la autora sino la evocación de una foto de la madre y su bebé, la autora misma: "photo you will/ mail to an American soldier/ you say is my father" (p. 45). El tono ha cambiado. El optimismo del poema inicial se cancela con la duda diseminada en el "you say is my father". La imagen del amor inocente sufrirá alteraciones cuando vemos que esta relación comenzó cuando el hermano de la madre le dijo al que sería el padre de la autora, "yes I have a sister" (p. 64). La frase funciona como el fragmento de un diálogo conocido en el código cultural: el soldado que busca con quién acostarse pregunta a un joven pobre si tiene una hermana, implícitamente comunica el deseo de acostarse con ella, y el joven responde que sí, iniciando la transacción. Esta posibilidad se refuerza en el poema "Green Morning in the Summer Forest" (pp. 62-63) donde vemos que la madre acepta a los soldados estadounidenses, "black/ stocking, silk and rare,/ a fine black line that 
ran the back/ of each firm calf'. De nuevo Magdaleno recurre al código establecido por el cine: los soldados compraban a las mujeres con las medias de seda que durante la guerra eran casi imposibles de conseguir. Otros versos la muestran en otra situación sacada directamente de ese mismo código:
The smoky nightclub
on Haunstetten Strasse, exotic, emerald earrings, the Gis whispering, Come here \& I will tell you how beautiful you are, gin $\&$ tonic, American martinis (p. 62).

En el contexto establecido en el poema anterior sobre la escasez imperante en la época, por una referencia a las cartillas de abastecimiento, uno se pregunta cómo consiguió la madre esos aretes de esmeraldas. La penúltima estrofa se concentra en la madre y su deseo que no se dirige hacia el padre, sino hacia la necesidad de sentirse querida.

\author{
My mother's leaving \\ $\&$ leaving again for those smoky \\ nightclubs, her need \\ to be loved \& loved \\ $\&$ loved, each night, \\ her beautiful legs (p. 63).
}

Como en "High Summer", Magdaleno enmarca el poema dentro de imágenes de la naturaleza alrededor de una metáfora: colibrí = madre. De allí el colorido de negro y esmeralda, el movimiento hiperactivo y frenético en busca de la dulzura, la aparente fragilidad y la belleza. Al principio, los pájaros aparecen sólo para evocar el recuerdo: "Hummingbirds appear-I think of my mother" (p. 62). Al final, sin embargo, la última estancia se dedica por completo a una pareja de colibríes cuyo vuelo culmina en el acto carnal: "the sudden, abrupt ascension/ into the 
green morning, frantic/ hearts, their love" (p. 63). Es decir, en vez del contexto ingenuo de inocencia juvenil celebrada dentro del corazón luminoso del hogar familiar, que tuvimos en la primera impresión sobre los padres, la autora revela otra escenografía teñida de corrupción mundana —el bar oscuro, el mercado negro, la prostitución-y lo funde con la sexualidad instintiva de los animales, mezcla de belleza — "the hummingbird's emerald chest/glistens in the morning" - y violencia dolorosa - "sting/ of the black ant"- donde el amor se expresa, en términos del intercambio, en esas cartillas de abastecimiento y las medias de seda que la madre llevaba sobre sus hermosas piernas: "black tickets of love". Si los lectores todavía no comprenden esta táctica de degradación, en "I Am the Daughter" (pp. 70-71) la autora dice que es la hija de la misma mezcla de belleza y sexualidad prohibida: "daughter/ of the edelweiss and the whore" (p. 70).

Sin embargo, debemos recordar que Magdaleno realiza esta desmitificación de su origen dentro de otro contexto, el de las referencias al discurso chicano. En ese discurso la figura de la Malinche, tanto de su imagen tradicional como de su reivindicación feminista, nos pide otra lectura. Todos los poemas acerca del abuso que sufrieron la madre y sus parientes femeninas, en la época nazi, equivale al maltrato que la Malinche recibió de su familia y sus dueños antes de la conquista española. ${ }^{4}$ En este contexto la colaboración de la madre tiene el aspecto de un comportamiento justificado por una lógica de sobrevivencia existencial y resistencia antipatriarcal. También, con la glorificación del mestizaje mismo, dentro de las teorías de lo híbrido multicultural, esta historia de transacciones sexuales pasa de ser inmoral a meramente real, el producto lógico de una lucha de fuerzas que ahora se entiende como el juego global entre las hegemonías que compiten por dominar el mercado y que explotan a las mujeres y a los jóvenes como los seres más vulnerables.

4 Bernal Díaz del Castillo, The Conquest of New Spain, trad. J. M. Cohen, Londres, Penguin Books, 1963, p. 85; Sandra Cypress, La malinche in Mexican Literature: From history to Myth, Austin, University of Texas Press, 1991, p. 33. 
La lectura de este libro desde la perspectiva "chicana" provoca otra pregunta: ¿esta dinámica desmitificadora es puramente unidireccional o contiene implicaciones también para el discurso chicano? Para responder podemos volver al concepto freudiano de lo unheimlich y sacarle más provecho. Freud dice que unheimlich "leads back to something long known to us, once very familiar". ${ }^{5}$ Indica algo que nos pertenece como parte de nuestro patrimonio casero. Sin embargo, por qué, simultáneamente, nos parece extraño, Freud dice que también implica "something withdrawn from the eyes of others, something concealed, secret [and even] hidden or dangerous". ${ }^{6}$ De esta manera, lo extraño y lo familiar son dos lados de lo mismo, lo propio que tenemos que esconder porque representa una amenaza. Por supuesto esto se puede aplicar a todo lo que Magdaleno encontró acerca de la relación entre sus padres. Dentro del ideal de la familia, del amor, de la seguridad de la casa, surge lo escondido, amenazante, de la realidad de su relación.

Homi Bhabha nos ayuda a llevar nuestro análisis a otro nivel. En "DissemiNation: Time, Narrative and the Margins of the Modern Nation", ${ }^{7}$ Bhabha interpreta lo unheimlich como el colectivo cultural reprimido. Contiene lo extraño o "supuestamente extranjero" que reside dentro de lo autóctono nativo; es decir, que lo nacional rechaza sus raíces que no concuerdan con la imagen autorizada, compuesta por los valores escogidos como más representativos. Más aún, las tilda de amenazantes y ajenas, cuando realmente pertenecen al patrimonio nacional. Bhabha convierte el unheimlich freudiano en lo inconsciente cultural nacional, en donde se archivan las historias reprimidas y las alternativas culturales negadas, ausentes del discurso oficial de la nación. Por eso estos elementos surgen en la producción cultural de los

5 Sigmund Freud, “The 'Uncanny' (1919)”, Papers on Applied Psychoanalysis, vol. 4 of Collected Papers, Toronto, Clarke, Irwin \& Co., 1956, p. 370.

6 Ibid., p. 377.

7 Homi Bhabha, "Dissemilnation: Time, Narrative and the Margins of Modern Nation", en Homi Bhabha [ed.], Nation and Narrative, Nueva York, Routledge, 1990, pp. 291322. 
grupos marginados, en esas voces ajenas y al mismo tiempo familiares. Estos grupos enuncian mensajes unheimlich desde la otredad cultural, con los cuales forman recuerdos perturbadores dentro del discurso nacional, recuerdos que amenazan la hegemonía que ese discurso pretende ejercer.

Marlene Dietrich, Rita Hayworth, \& My Mother representa la intervención de lo unheimlich chicano. Al hablar del sueño ideal del origen mestizo, inmediatamente dialoga con el centro del discurso público. La imagen inicial de la colección recuerda el idealismo de los primeros postulados del chicanismo. Luego la dismitificación del ideal recuerda el discurso de las feministas chicanas que han cuestionado la misoginia del patriarcado chicano. Pero la desmitificación ha llegado a ser un discurso público, bastante conocido por los lectores y autorizado por las instituciones académicas. Ya no es ni extraño ni amenazante, sino, como también explica Bhabha, uno de esos elementos marginales que el centro apropia para crear su imagen de nacionalismo heterogéneo y simultáneamente unido. Entonces lo verdaderamente unheimlich del libro de Magdaleno tendría que provenir de otros elementos que el discurso chicano también mantiene marginados. Y así es.

Magdaleno hace hincapié en el racismo que divide familias, esto lo muestra, sobre todo, en la figura de su tío que pertenecía a las camisas negras de Hitler. Este racismo esconde una actitud en contra de cualquier mezcla con grupos percibidos como ajenos, por eso Magdaleno opone en ese momento su propia imagen de mestiza con corazón azteca. ¿Cómo no ver una denuncia de la misma actitud que permea el discurso chicano de nacionalismo cultural, discurso que continuamente vilipendia al otro "anglo" o "euro" americano con esencialismos que revelan un prejuicio equivalente al del tío de los poemas? El discurso nazi se duplica en el discurso estadounidense, efectivamente, pero al multiplicarse las perspectivas, el discurso chicano surge como otro "doble" del discurso nacional estadounidense tan odiado, una repetición involuntaria ${ }^{8}$ que surge desde

8 Freud, op. cit., p. 390. 
dentro de su misma producción como algo reprimido que vuelve para revelar los vínculos fundamentales con el otro, lo que el discurso público quiere eliminar. Los prejuicios contra el mestizaje llegan a ser lo familiar reprimido de cualquier nacionalismo cultural. Bhabha probablemente vería la literatura chicana como el doble de la estadounidense autorizada: "scraps, patches, and rags of daily life [that] must be repeatedly turned into the signs of national culture". ${ }^{10}$ Pero en Magdaleno, al poner lo chicano dentro del código de lo estadounidense - el soldado chicano es el "American G.I." - borra esa diferencia para mostrar que el binarismo de Bhabha es demasiado simplista. Al triangular las fuerzas culturales - tres idiomas comparten la estructura textual aquí - todo se multiplica, se fragmenta. Dentro de un juego nacional, lo reprimido se convierte en el doble silenciado de la identidad dominante. Pero cuando ese fenómeno cultural nacional se ve desde una perspectiva internacional, el doble minoritario toma el aspecto de la parte esencial del "Uno" de esa nación. El doble que se ve - y quiere verse- como el marginado representa, por decirlo así, "otro doble" en el discurso central al salir al extranjero, convirtiéndose en lo autorizado de su otro nacional frente a Otro internacional. De esta manera se van bifurcando los absolutos hasta mostrar que todos comparten lo escondido, lo reprimido en una escenografía global. Así, el fascismo violento llega a ser una posibilidad de cualquier grupo nacionalista, aun el chicano. Magdaleno crea bastantes imágenes de la protagonista - de corazón azteca - como una persona capaz de comportarse como una turista gringa, o de su padre chicano que hizo el papel de conquistador en una generación antes, o de su familia chicana que insultó a la madre con clichés de prejuicio antigermánico.

Quizá el descubrimiento de "otro doble" en todo discurso nacionalista explique el último poema de la colección. Para formar un marco con el primer poema, analizado arriba, el último parece fuera de la tercera sección de la colección y sin número de página impresa. Ubicado como un

9 Ibid., p. 394.

${ }_{10}$ Bhabha, op. cit., p. 297. 
paratexto que no pertenece a ninguna de las secciones enumeradas de la colección, sino a otro nivel abarcador o trascendente, el poema comenta sobre la totalidad desde una perspectiva privilegiada de marco que forma con el primer poema, así como arco que pasa simultáneamente a través y por encima del desarrollo textual. "Cordate Envoy" (p. 95) ofrece la imagen de una hoja de planta o árbol que la autora contempla una tarde. El uso ya codificado de leaf u hoja como metáfora de la página es sugerente en este contexto: la autora hace una lectura final. La palabra envoy apoya esta interpretación. Mientras su denotación más coloquial en inglés es de mensajero o representante, su primera definición es de un mensaje mismo, específicamente en el sentido de envoi - y con esto Magdaleno añade el francés a su juego políglota. Envoi quiere decir un comentario final a un texto, sobre todo la última estancia de un poema que clarifica la moraleja o sentido de la obra y casi siempre va dirigido a la persona a quien se ha dedicado el poema. Magdaleno subraya la importancia de este último comentario al darle la forma de corazón - cordate. Es decir, nos ofrece una revelación final desde el corazón y en forma de mensaje del corazón. Pero ya no es el corazón azteca que la autora utilizó en la confrontación con el tío nazi — que ahora representa doblemente el prejuicio encarnado en el tío. Quizá la revelación del fascismo latente en el nacionalismo o el prejuicio descubierto en su familia méxico-americana hayan modificado su propia apelación al nacionalismo cultural posible en aquel entonces, pidiendo ahora una vuelta al corazón desde una perspectiva ya no limitada por ningún nacionalismo cultural. Dentro del código establecido por el proceso textual, Magdaleno ha ubicado esa posibilidad una y otra vez en el reino de la naturaleza. No sorprende, entonces, que al final Magdaleno recurra a una lectura de la naturaleza misma en forma de una hoja.

Significativamente Magdaleno enfatiza la estructura de orden natural de la hoja: la organización alrededor de un eje central que le da equilibrio al conjunto. Ese eje aparece como una vena central, que bien podría ser una alusión a la frontera que divide en dos un solo país, pero aquí sirve para crear la unión, no la división. De esta arteria central salen "regimented lines" para reforzar la impresión de orden del cual 
emerge la evocación de la madre. Sobre este trasfondo aparece la hija en la forma de "Brown spots, small imperfections... like the ones I will carry/ on the surface of my own hands." La madre y la hija aparecen en el mismo espacio, relacionadas dentro de un código de señas pertenecientes a un mismo fenómeno vital, un mismo sistema ecológico. Esta unión de la madre e hija dentro del corazón, que es también la materia misma del mundo, dialoga con y responde a la imagen de separación de esos elementos en "Grenze", el poema con que comenzó la primera sección, que se expresó como la división de esos mismos elementos. El viaje por el texto ha conducido a esta posibilidad de lograr la reunión entre hija y madre que se buscaba desde el principio.

Sin embargo, la especificidad de los lugares donde aparecen la madre y la hija en la hoja no debe pasarse por alto. Cada una pertence a un subcódigo distinto: la madre está relacionada al orden del sistema circulatorio central, mientras que la hija a las imperfecciones que manchan la perfección del orden - podríamos decir que aparece en lo abyecto del sistema como una amenaza a su pureza. No por nada dice Magdaleno que las manchas son de color café, el color que se asocia al mexicoamericano o que en Alemania se asociaba al judío. Tampoco debemos pasar por alto que de esta manera Magdaleno crea en su último poema otro avatar de la relación entre lo autorizado y lo marginado. Pero en la última oración, de cinco versos, la autora dice que alza la hoja para verla traspasada por la luz del sol. En la luz cósmica - iluminación trascendental no limitada por las divisiones y prejuicios terrestres - la hoja deja de ser un juego de generaciones o etnias o naciones y pide la lectura desde otro código, que se expresa en forma de "pinholes of light", señas de cuando, a pesar del orden oficial y su doble resistencia, las fuerzas vitales esenciales lograron expresarse. No por nada, al enumerar esas fuerzas, incluye al viento y al dolor, esta última palabra es la misma que había usado al hablar de la muerte de los niños inocentes en la guerra. Es decir, que lo que se lee a través de la superficie del orden y su contradiscurso es lo esencial de la experiencia humana, que altera cualquier lectura superficial del dolor, que como el viento se encuentra por todo 
el mundo. Pero esa esencia no salta a la vista en la primera impresión, sino requiere una lectura iluminada y sensible de lo que se siente como una ausencia casi invisible. Magdaleno implícitamente sugiere que hagamos lo mismo con Marlene Dietrich, Rita Hayworth, \& My Mother: lecturas en muchos niveles, pero, sobre todo, una que vaya más allá de los discursos establecidos y los prejuicios obvios. 
BIBLIOGRAFÍA

BHaвHA, Homi K, "DissemiNation: Time, Narrative, and the Margins of the Modern Nation," en Homi K. Bhabha [ed.], Nation and Narration, Nueva York, Routledge, 1990, pp. 291-322.

Bruce-novoA, Chicano Poetry, A Response to Chaos, Austin, University of Texas Press, 1982.

CyPRESS, SANDRA, La Malinche in Mexican Literature: From History to Myth, Austin, University of Texas Press, 1991.

Díaz Del Castillo, Bernal, The Conquest of New Spain, trad. J. M. Cohen, Londres, Penguin Books, 1963.

Freud, Sigmund, “The 'Uncanny' (1919)," Papers on Applied Psychoanalysis, vol. 4 of Collected Papers, Toronto, Clarke, Irwin \& Co., 1956, pp. 369-407.

Hoz, Claudia DE LA, http://members.tripod.com/ claudia79/early. html

Magdaleno, Rita María, Marlene Dietrich, Rita Hayworth, \& My Mother, Tucson, University of Arizona Press, 2003. 